УДК $532.517 ; 532.528$

DOI

\title{
ДОСЛІДЖЕННЯ КАВІТАЦЙНИХ ЕФЕКТІВ В НАСОСАХ РІЗНИХ ТИПІВ
}

\author{
Авдєєва Л.Ю. д-р техн. наук, с.н.с., Макаренко А.А. к.т.н., Жукотський Е.К., \\ Інститут технічної теплофізики НАН України, м. Київ
}

\begin{abstract}
Анотація. Насоси широко використовуються в більшості технологічних процесів хімічної $і$ харчової промисловості, в т.ч. в апаратах для інтенсифікації процесу отримання мікро- $і$ наноемульсій за рахунок виникнення ефектів гідродинамічної кавітації. Використання кавітаційних технологій дозволяє збільшити продуктивність технологічних процесів, забезпечити значну економію енерговитрат і високу якість обробки дисперсних систем. В технологічних схемах кавітаційних апаратів використовуються насоси різних типів. Виникнення в них кавітаиійних ефектів призводить до негативних наслідків в результаті яких відбувається зниження продуктивності і ККД всього пристрою і руйнування поверхонь робочих органів. Найбільшого застосування знайшли динамічні лопатеві і об'ємні (гвинтові або шестеренні) насоси.

В роботі представлені результати досліджень виникнення кавітаційних ефектів в динамічному відиентровому і в об' 'мному шестеренному насосах за зміною температурних і електрохімічних показників води в результаті обробки. Аналіз результатів досліджень температурних показників продемонстрували відмінності принципу дії обраних насосів за їх впливом на оброблюване середовище. В динамічному відцентровому насосі температурні показники швидко наростають, на відміну від об'ємного шестеренного, в якому за 20 хв. роботи підвищення температури практично не відбулося. В результаті активного динамічного впливу на молекулярному рівні при проходження рідини через відиентровий насос рівень рН збільшується вже з перших секунд обробки. Значення питомої електропровідності води змінюються так само більш виражено для динамічного відцентрового насосу. Отримані результати вказують на активацію води з утворенням електронно-збуджених станів молекул. Таким чином, встановлено виникнення кавітації в динамічному відиентровому насосі при певних умовах і параметрах його роботи.
\end{abstract}

Ключові слова: гідродинамічна кавітація, кавітаційні технології, насоси, небажані кавітаційні ефекти, електрохімічні властивості

\section{RESEARCH OF CAVITATION EFFECTS IN DIFFERENT TYPES OF PUMPS}

\author{
Avdieieva L. Yu. Dr.Tech.Sc., Senior Research Officer, Makarenko A. A. Ph. D, Zhukotskyi E. K. \\ Institute of Engineering Thermophysics of the National Academy of Sciences of Ukraine, Kyiv
}

\begin{abstract}
Pumps are widely used in most technological processes of the chemical and food industry, including for the intensification of the process of obtaining micro- and nanoemulsions due to the effects of the hybrid dynamics cavitation. Applied cavitation technologies can increase the productivity of technological processes; provide significant energy savings and high-quality processing of disperse systems. The efficiency of technological processes and the quality of food products depends on the reliable operation of all equipment. However, uncontrolled cavitation can lead to serious failures in the operation of equipment and even the destruction of the structure. In technological schemes of cavitation devices, pumps of different types are used. Creation of cavitation effects in them leads to negative consequences resulting decreasing of productivity and efficiency of the entire device and the destruction of the surfaces of working bodies. The most used are dynamic centrifugal and volumetric (screw or gear) pumps. The operation of centrifugal pumps is based on the general principle - the power interaction of the impellers of the rotor with the surrounding fluid flow, which is constantly connected to the pump inlet and outlet nozzles. Stable operation of the centrifugal pump is provided in such a mode, when the absolute pressure at all points of its inner cavity is greater than the pressure of saturated vapor of the pumped liquid at a given temperature. If this condition is not met, then the development of hydrodynamic cavitation and its associated effects begins, which leads to a decrease in the productivity or even the termination of the pump operation. In volumetric gear pumps, the working fluid is provided, from the working volume intermittently, portions are displaced from the specified volume by the force elements in such a way that in these hydromachine the input is constantly and very tightly disengaged with the output, by a strong and hermetic contact of gears teeth with each other. Such a method of work in general does not provide conditions for discontinuities in the flow and the occurrence of cavitation, but under certain conditions in the gaps between the teeth of the gears, local areas of reduced pressure may occur.

The paper presents the results of research on the appearance of cavitation effects in dynamic centrifugal and volumetric gear pumps by changing the temperature and electrochemical parameters of water as a result of
\end{abstract}


processing. The analysis of the results of studies of temperature indices showed differences in the principle of the operation of selected pumps for their influence on the processed environment. In a dynamic centrifugal pump, the temperature indices rapidly increase, unlike the volume gear, in which, for 20 minutes, the temperature increase practically did not occur. As a result of the active dynamic effect at the molecular level, when the liquid passes through a centrifugal pump, the $\mathrm{pH}$ level increases with the first seconds of processing. The value of the electrical conductivity of the water for a dynamic centrifugal pump varies the same way. The obtained results indicate the activation of water with the formation of electron-excited states of molecules. Thus, it is established that cavitation occurs in a dynamic centrifugal pump under certain conditions and parameters of its operation.

Keywords: hydrodynamic cavitation, cavitation technologies, pumps, unwanted cavitation effects, electrochemical properties.

Вступ. На сьогодні накопичений значний досвід по використанню гідродинамічної кавітації для інтенсифікації процесів масообміну - перемішування, розчинення, диспергування, емульгування та ін., які відносяться до енерговитратних. Інтенсивність кавітаційного впливу залежить від властивостей середовищ і гідродинамічних умов в потоці, які розрізняються для різних типів місцевих опорів, їх конструктивних особливостей і геометричних характеристик $[1,2]$.

Необхідним обладнанням для роботи будь-якого гідродинамічного кавітаційного апарату є насоси. Насоси представляють собою гідравлічні машини, які призначені для переміщення рідини під напором, перетворюючи механічну енергію привідного двигуна в механічну енергію рідини, що рухається. Насоси дозволяють піднімати рідину на певну висоту, подавати ії на необхідну відстань в горизонтальній площині або циркулювати в певній замкнутій системі. Насоси широко використовуються в більшості технологічних процесів хімічної і харчової промисловості, в т.ч. для інтенсифікації процесу отримання мікро- і наноемульсій за рахунок ефектів гідродинамічної кавітації. Від їх роботи залежить ефективність проходження технологічних процесів і якість харчових продуктів [3, 4].

Аналіз проблематики та останніх досліджень. Всі насоси за принципом дії поділяються на два основних види: динамічні та об'ємні. Динамічні насоси поділяються на лопатеві насоси, насоси тертя та насоси інерційного типу. Найбільшого поширення набули лопатеві насоси. В динамічних лопатевих насосах рідина під впливом гідродинамічних сил переміщується в камері, що постійно сполучена з вхідним і вихідним патрубками насоса $[3,4,5]$.

Лопатеві насоси, у свою чергу, діляться на відцентрові й осьові, причому у відцентрових насосах рідина рухається крізь робоче колесо від його центра до периферії, а в осьових - у напрямку осі колеса. За кількістю робочих коліс такі насоси бувають одно-і багатоступінчасті. Одноступінчаті насоси (насоси з одним робочим колесом) здатні забезпечувати невеликий тиск. Якщо необхідний високий напір, то використовують багатоступінчасті агрегати з розташованими послідовно поруч робочих коліс. Виконання насоса може бути 3 відкритим і закритим робочим колесом. Використання насоса з відкритим робочим колесом виключає утворення застійних зон і забезпечує легку промивність, а також дає можливість перекачувати рідини з високим вмістом зважених частинок. [3, 6]

В харчовій промисловості відцентрові насоси використовуються, як правило, при виробництві мало-і середньо в'язких продуктів - молока і молочних продуктів, пива та безалкогольної продукції і т.д. Не менш часто відцентрові насоси застосовуються на лініях подачі і проштовхування рідин через теплообмінні апарати, фільтри та сепаратори, в установках для циркуляційної безрозбірного промивки і безрозбірного стерилізації (SIP) [3, 7].

В об'ємних насосах рідина переміщується за рахунок періодичної зміни об'єму робочої камери, що поперемінно сполучається з вхідним і вихідним патрубками насоса. До них відносяться поршневі, пластинчасті, мембранні, гвинтові, шестеренні, перистальтичні. Серед об'ємних насосів найбільшого застосування набули гвинтові і шестеренні $[4,8]$.

Шестеренні насоси - це об'ємні насоси роторного типу, робочими органами яких є дві або більше шестерні, що утворюють зчеплення. Основна група шестеренних насосів складається з двох прямозубих шестерень зовнішнього зачеплення. Застосовуються також інші конструктивні схеми, наприклад, насоси з внутрішнім зчепленням, шестеренні насоси з трьома або більше шестернями. Шестеренні насоси найчастіше використовуються в найпростіших системах з відносно низьким рівнем тиску (близько 140-180 бар або 14-18 МПа). Шестеренні насоси дуже прості за конструкцією, містять малу кількість деталей, відносно дешеві і менш чутливі до забруднень в порівнянні з іншими гідравлічними насосами $[8,9]$.

Завдяки простоті і технологічності конструкції, шестеренні насоси отримали широке застосування для живлення гідроприводів невеликої потужності, для подачі мастила, а також для живлення систем управління. Шестеренні насоси відрізняються компактністю, малою кількістю рухомих деталей, надійністю в роботі. Найбільшого поширення набули шестеренні насоси з конструкцією, що складається 3 шестерень 3 однаковою кількістю зубців. Робоча рідина переноситься із зони всмоктування насоса в зону нагнітання за допомогою порожнин, що утворюються при зачепленні зубців шестернею $[3,8]$.

Наукові праці, Том 83, випуск 1 Scientific Works, Volume 83, Issue 1 
Відцентрові та шестерні насоси активно використовуються в технологічних схемах кавітаційних апаратів. Вибір типу проводиться в кожному конкретному випадку з урахуванням його експлуатаційних і конструктивних якостей, а також технологічного призначення насоса $[1,2]$.

Метою роботи було дослідження виникнення кавітаційних ефектів в різних типах насосів кавітаційних апаратів за зміною температурних і електрохімічних показників води в результаті обробки.

Матеріали та методи дослджень. Для проведення досліджень були використані гідродинамічний відцентровий і об'ємний шестеренний насоси. Робота лопатевих насосів основана на загальному принципі - силовій взаємодії лопатей робочого колеса $з$ оточуючим потоком рідини, яка постійно сполучена 3 вхідним і вихідним патрубками насоса. Рідина надходить через отвір в передньому диску робочого колеса по всмоктуючому патрубку і всмоктуючому трубопроводу. Рух рідини по всмоктуючому трубопроводу відбувається внаслідок різниці тисків над вільною поверхнею рідини в приймальному басейні (атмосферний тиск) і в центральній області колеса (зона розрідження)[6]. Стабільна робота відцентрового насосу забезпечується в такому режимі, коли абсолютний тиск у всіх точках його внутрішньої порожнини більше тиску насичених парів рідини, що перекачується, при даній температурі. Якщо така умова не виконується, то починається розвиток явища кавітації, що призводить до зменшення продуктивності чи навіть припинення роботи насосу[3]. Витрати рідини в значній мірі залежать від тиску на виході з насоса, тобто - від зовнішнього навантаження. В об'ємних шестеренних насосах робоча рідина подається з робочого об'єму переривчасто, порціями витісняється із зазначеного об'єму силовими елементами таким чином, щоб в цих гідромашинах вхід постійно і дуже герметично роз'єднаний з виходом, за допомогою міцного і герметичного контакту зубів шестерень між собою[8]. Такий спосіб роботи загалом не передбачає умов для виникнення розривів потоку і кавітації, але при певних умовах роботи насосу в зазорах між зубами шестерень можуть виникнути місцеві зони зниженого тиску [1012].

При виникненні явища кавітації в насосах відбуваються суттєві зміни їх роботи: знижується продуктивність, тиск, потужність, ККД, відбувається хімічне руйнування і кавітаційна ерозія поверхонь робочих органів, виникає шум і вібрація насоса, в результаті якої порушується герметичність з'єднань і ущільнень насоса, підвищується температура в місцях зхлопування парогазових кавітаційних бульбашок і кумулятивного впливу на поверхню металу[1-4] .

Схема використаного кавітаційного апарату детально описана в роботах [13]. В дослідженнях використовувалась свіжо відібрана вода водогону. Температурні показники визначались за допомогою портативного електронного термометра з виносним датчиком марки HI 98509 Checktemp 1 (виробник Hanna Instruments, Німеччина) з похибкою вимірювання $\pm 0.3^{\circ} \mathrm{C}$, значення $\mathrm{pH}$ - портативного рн-метра марки НI 98128 PHер5 (виробник Hanna Instruments, Німеччина) з похибкою вимірювання $\pm 0.05 \mathrm{pH}$, значення питомої елетропровідності - портативного кондуктометра HI 98303 DiST 3 з похибкою вимірювання \pm 2\% (виробник Напnа Instruments, Німеччина).

Результати досліджень. Дослідження зміни температурних показників при роботі насосів різних типів впродовж 20 хв. наведені на рис.1.

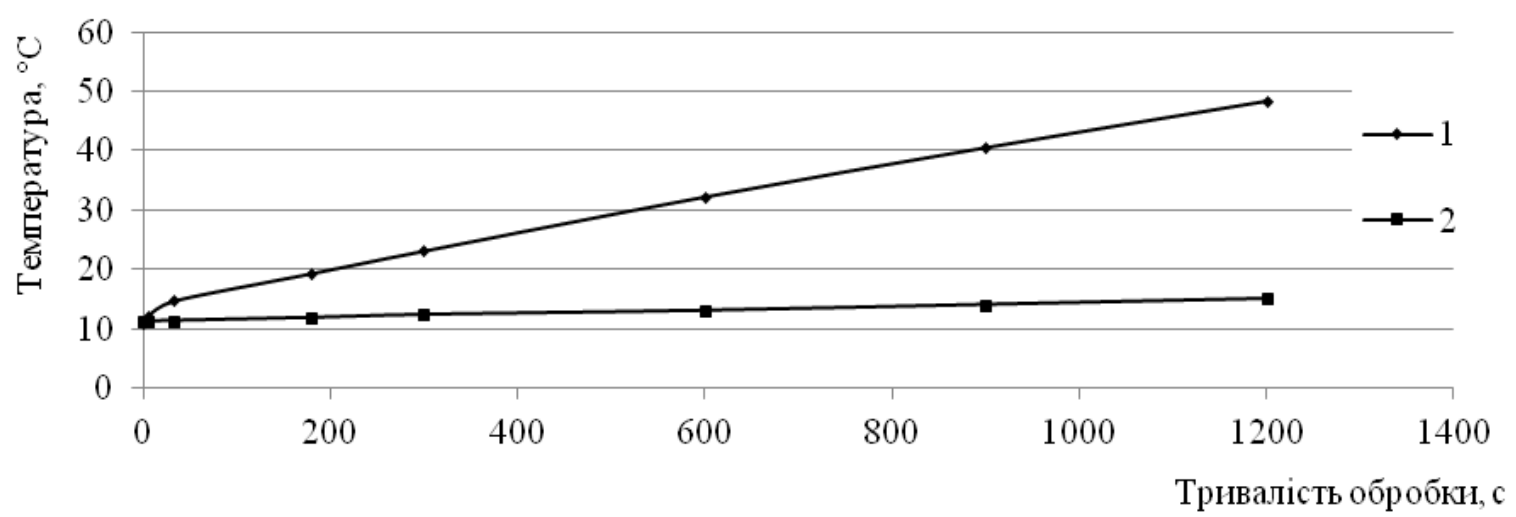

1 - динамічний відиентровий насос; 2 - об'ємний шестеренний насос

Рис.1 - Залежність температури від тривалості обробки води в насосах

Аналіз одержаних результатів (рис.1) продемонстрували відмінності принципу дії обраних насосів за їх впливом на оброблюване середовище. В динамічному відцентровому насосі температурні показники швидко наростають. На відміну від об'ємного шестеренного, в якому за 20 хв. роботи підвищення температури відбувається на $4{ }^{\circ} \mathrm{C}$ або в 1,4 рази, у динамічному відцентровому відповідні показники наростають набагато швидше, в 4,4 рази. Різниця температур середовищ, оброблених в насосах різних типів становила більше $30{ }^{\circ} \mathrm{C}$. Значне підвищення температури оброблюваного середовища у відцентровому насосі можна пояснити

Наукові праці, Том 83, випуск 1 Scientific Works, Volume 83, Issue 1 
виникненням розрідження в центральній частині насосу що призводить до розривів суцільності рідини 3 утворенням парогазових кавітаційних бульбашок.

В процесі роботи насосу вони разом із середовищем зносяться по каналах в зону підвищеного тиску до периферії і дифузору. При цьому утворені бульбашки зростають і зхлопуються з виділенням потужного імпульсу енергії, що і призводить до прояву різноманітних кавітаційних ефектів і багатофакторному впливу на оброблюване середовище. В результаті змінюються хімічні, фізичні і структурні властивості оброблюваних рідких дисперсних систем $[1,2,14,15]$. В об'ємних насосах, на відміну від відцентрових, рідина рухається циклічно, порціями. При їх роботі рідина всмоктується і заповнює порожнини між зубцями під атмосферним тиском, тому виникнення кавітаційних ефектів майже виключається [10, 11].

Розвиток кавітації у воді призводить до випромінювання значної частини енергії під впливом зхлопування кавітаційних бульбашок. В результаті відбувається розщеплення молекул води і активація води 3 появою вільних водневих зв'язків, зміна фізико-хімічних і електрохімічних властивостей. До показників, якими характеризуються такі зміни є водневий показник (pH), окисно-відновний потенціал (ОВП), питома електропровідність та ін. Водневий показник $(\mathrm{pH})$ - це міра активності вільних іонів водню у воді.

Величина рН визначається кількісним співвідношенням у воді іонів $\mathrm{H}+\mathrm{i} \mathrm{OH}-$, що утворюються при дисоціації води. При розчиненні у воді хімічних речовин або під дією різних видів фізичних впливів співвідношення іонів може бути порушено, що приводить до зміни значень $\mathrm{pH}$.

Електропровідність - фізична величина, що кількісно характеризує здатність тіла проводити електричний струм під впливом дії електричного поля. За молекулярною будовою вода теоретично відноситься до полярних діелектриків. Будучи хорошим розчинником, вода $\epsilon$ досить хорошим провідником. Електропровідність води обумовлена вмістом в ній електролітів. В залежності від розчинених домішок ії електропровідність може змінюватися на багато порядків.

Результати досліджень показників рН води після їі обробки в обраних насосах наведені на рис. 2.

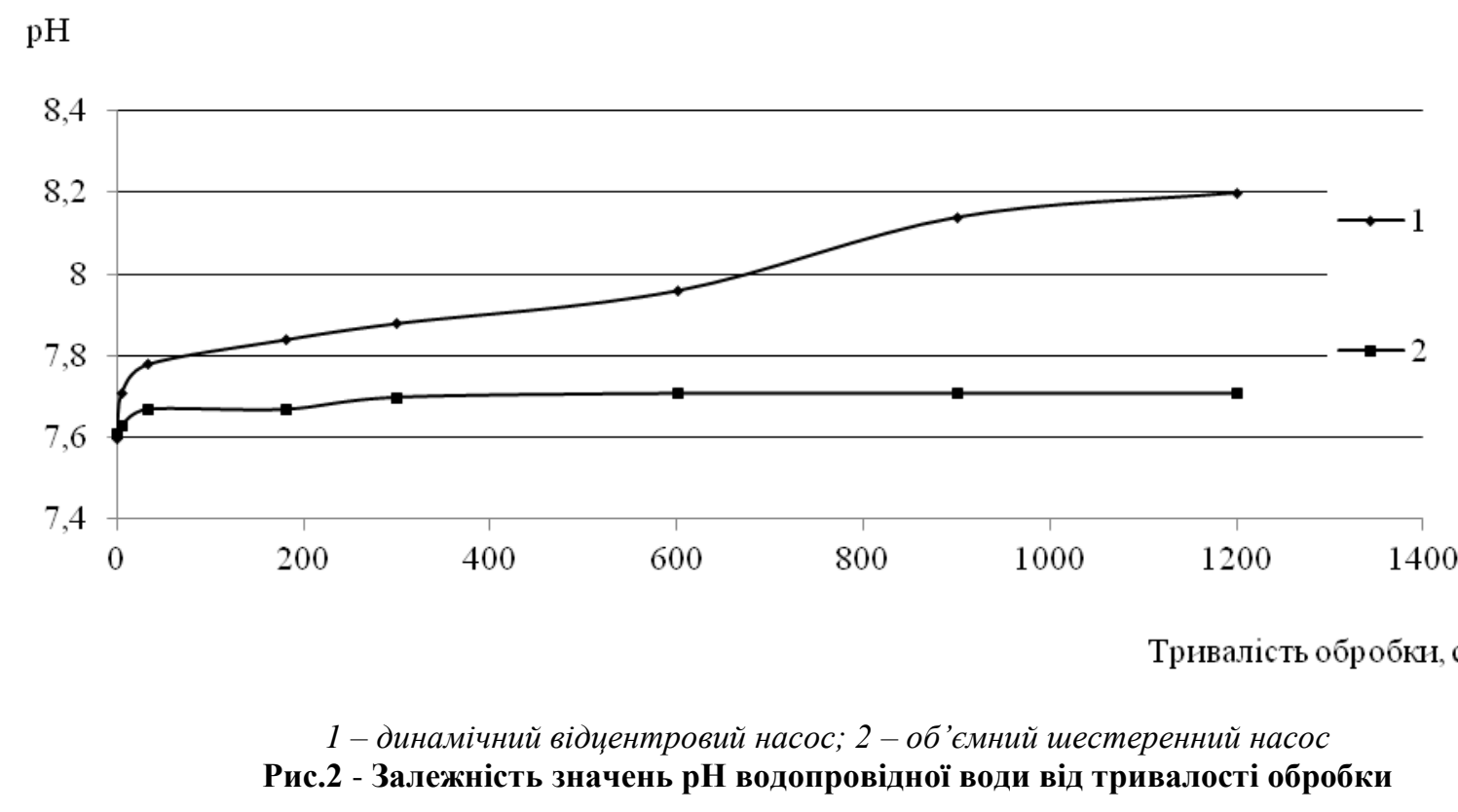

На рис.2 представлені результати досліджень рН зразків водопровідної води після обробки в обраних типах насосів. В обох типах насосів найбільші зміни показників відбуваються в результаті перших 8-16 с обробки. При подальшій обробці рідини у відцентровому насосі зростання дослідного показника продовжується. В результаті активного динамічного впливу цього насосу на структуру води на молекулярному рівні відбувається її подальша активація. Вже після першого циклу обробки значення рН води обробленої у відцентровому насосі досягають значень цього показника для зразка води, одержаного при циклічному прокачуванні в об'ємному шестеренному насосі впродовж 92 циклів. Після 20 хв. обробки води рівень рН змінюється на 0,5 одиниці.

Результати досліджень питомої електропровідності води після їі обробки в обраних насосах наведені на рис. 3. 


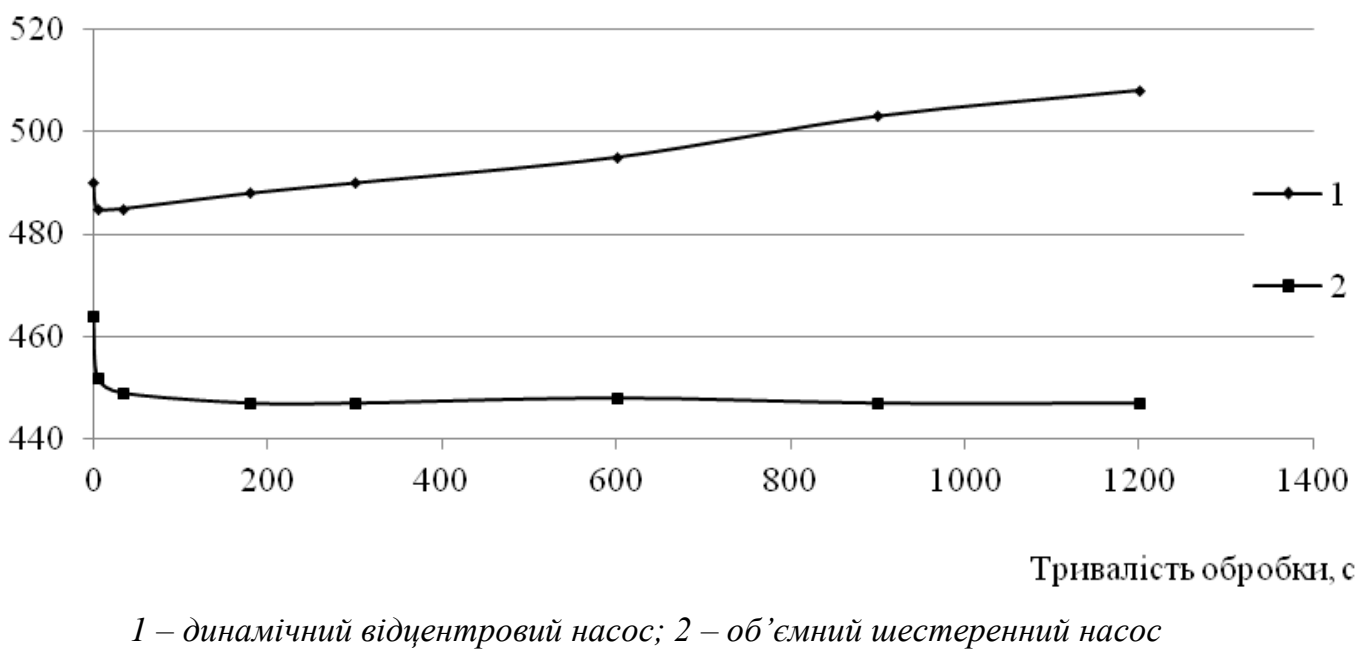

Рис.3 - Залежність значень питомої електропровідності водопровідної води від тривалості обробки

На рис.3 представлені результати досліджень питомої електропровідності зразків після обробки в обраних типах насосів. В обох типах насосів найбільші зміни показників відбуваються в результаті перших циклів обробки. Значення питомої електропровідності для зразка води, обробленої в шестеренному насосі після третього циклу обробки залишаються майже незмінними.

Для зразка води, обробленого в динамічному відцентровому насосі значення цього показника змінюються набагато більш виражено. Отримані нами результати досліджень підтвердили висновки, зроблені в результаті аналізу даних досліджень (рис.1, рис.2) про активний вплив ефектів гідродинамічної кавітації в динамічному відцентровому насосі. Отримані результати вказують на активацію води з утворенням електронно-збуджених станів молекул.

Дослідження зміни рН дослідних зразків водопровідної води після обробки в насосах різних типів при подальшій витримці при температурі $20 \pm 2{ }^{\circ} \mathrm{C}$ впродовж 24 годин показані на рис. 4.

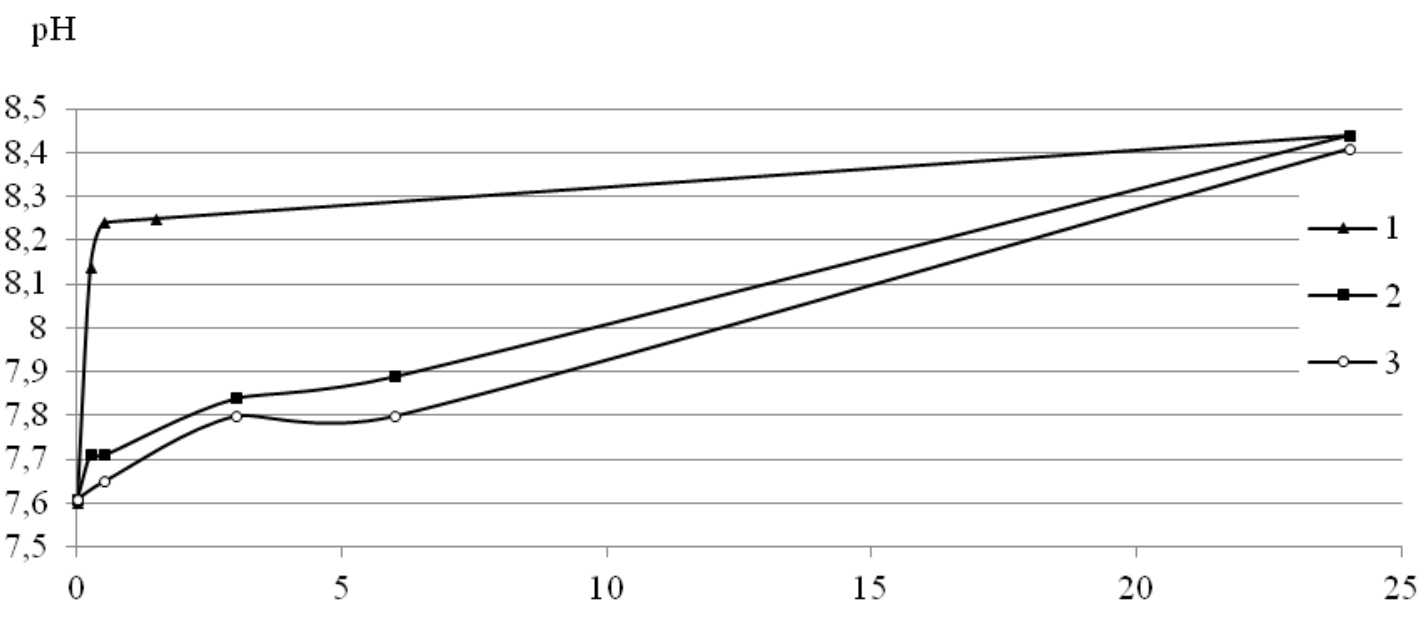

Тривалість витримування, год

1 - динамічний відцентровий насос; 2 - об'ємний шестеренний насос, 3- контроль

Рис.4 Залежність зміни рН водопровідної води від тривалості відстоювання без обробки та після 15 хв. обробки в насосах

Обговорення результатів досліджень. Аналіз одержаних результатів (рис. 4) показав, що рівень $\mathrm{pH}$ продовжує поступово незначно підвищуватися як у дослідних, так і у контрольному зразках води. Використання об'ємного шестерного насосу практично не призводить до зміни рівня рН, порівняно до контролю. Активація води в результаті обробки у відцентрового насосу зберігається ще впродовж доби, але поступово 
знижується і після 18-20 годин витримки наближається до відповідних значень контрольного зразка необробленої водопровідної води.

Проведені дослідження показали наявність гідродинамічної кавітації при роботі динамічного відцентрового насосу. Для виключення некерованої кавітації і попередження збоїв в роботі обладнання, особливо в технологічних схемах кавітаційних технологій, бажано використовувати насоси що не піддаються впливу кавітації, наприклад об’ємні.

При їх роботі рідина всмоктується і заповнює порожнини між зубцями під атмосферним тиском, тому виникнення кавітаційних ефектів майже виключається. В разі необхідності за експлуатаційними або технічними характеристиками використання динамічних насосів, потрібним є використання обладнання 3 поліпшеною якістю матеріалів та застосовуванням захисних покриттів деталей, найбільш схильних до дії кавітації і стирання або конструкції з антикавітаційними властивостями.

\section{Висновки}

Насоси різних типів широко використовуються в технологічних схемах кавітаційних апаратів різного призначення. При цьому є велика ймовірність виникнення негативних кавітаційних ефектів в насосах, що може проявлятися через зниження продуктивності і ККД всього пристрою, а також руйнування поверхонь робочих органів.

На прикладі досліджень зміни температурних показників, величини $\mathrm{pH}$ і питомої електропровідності показано зміну фізичних і хімічних властивостей води водогону обробленої в насосах різних типів. В ході досліджень доведено суттєві зміни цих показників в динамічному відцентровому насосі, що свідчить про виникнення гідродинамічної кавітації при його роботі.

\section{References.}

1. Promtov, M.A. (2008) Perspektivy primeneniya kavitatsionnykh tekhnolohiy dlya intensifikatsii khimikotekhnolohicheskikh protsessov. Vestnik THTU. 14(4) 861-869.

2. Braeutigam, P., Franke, M., Zhi-Lin, Wu, Ondruschka, B. (2010) Role of Different Parameters in the Optimization of Hydrodynamic Cavitation. Chem. Eng. Technol., 33(6), 932-940.

3. Ostrikov, A. N., Krasovitskij, Ju. V., Shevtsov, A. A. i dr. (2006) Protsessy i apparaty pischevyh proizvodstv. $\mathrm{SPb}$.: GIORD, 1, 632.

4. Karelin, V.Ya., Minaev, A.V. (1986) Nasosyi i nasosnyie stantsii: Ucheb. dlya vuzov. M.: Stroyizdat,. 320.

5. Lyamaev, B.F. (1988) Gidrostruynyie nasosyi i ustanovki. L.: Mashinostroenie, 256.

6. Fedorets', V.O., Pedchenko, M.N., Strutins'kij, V.B. ta in. (1995) Gidroprivodi ta gidropnevmoavtomatika: pidruchnik. K:Vischa shkola, 463.

7. Loginov, A. V., Slyusarev, M. I., Smirnyih, A. A. (2001) Nasosyi i nasosnyie ustanovki pischevyih predpriyatiy [Tekst]: Uchebnoe posobie. Voronezh. gos. tehnol. akad., Voronezh. 220.

8. Kulinchenko, V. R. (2006) Gidravlika, gidravlichni mashini i gidroprivid: PidruchnikKiïv: «Inkos», Tsentr navchal'noï literaturi, 616.

9. Chumakov, G.A., Lunjaka, K.V., Krivenko, S.V. (2009) Kurs lektsij z distsiplini "Gidravlika i gidro-, pnev-moprivod": Navchal'nij posibnik Herson, HNTU, 121.

10. Jahno, O. M., Kostjuk, D.V., Strichek, Ja., Antonjak, P. (2012) Vlijanie kavitatsii na velichinu pul'satsij podachi shesterennogo nasosa. Visnik NTUU «KPI», Serija Mashinobuduvannja, 64, 132-135.

11. Miroshnichenko, S.T., Koval', V.A, Epifanov, S.A. (2010) Otsenka kavitatsionnogo protsessa v nasosnom oborudovanii metodom vibroakusticheskoj diagnostiki. Visnik NTUU «KPI», Serija Mashinobuduvannja, 59, 173 175.

12. Patrick Braeutigam, Zhi-Lin Wu, Annegret Stark, Bernd Ondruschka (2010) Roles of Pumps and Bypass in Chemistry Induced by Hydrodynamic Cavitation. Chem. Eng. Technol., 33(2), 341-346.

13. DolInskiy, A.A., Avdeeva, L.Yu., Zhukotskiy, E.K., Makarenko, A.A. (2014) Vpliv gIdrodinamIchnoYi kavstatssyi na obrobku skladnih geterogennih sistem Promyishlenaya teplotehnika., 36(5), 5-10.

14. Lesya Yu. Avdeeva, Eduard K. Zhukotskyi, Andrii A. Makarenko (2018) The Effects of hydrodynamic cavitation for the change of water temperature indicators. XVII International scientific conference "Improvement of processes and equipment in food and chemical industries" Abstracts. Ukraine, Odessa, September 3-8th,. 12.

15. Avdeeva, L.Ju., Makarenko, A.A. (2017) Vpliv efektiv gidrodinamichnoï kavitatsiï na elektrohimichni vlastivosti vodi. Naukovi pratsi Odesa, 81(1), 105-110.

Отримано в редакцію 09.04.2019

Прийнято до друку 20.06.2019
Received 09.04.2019

Approved 20.06.2019 